\title{
KOMPOSIT DEGRADABEL POLIETILENA TEREFTALAT DENGAN SELULOSA MENGGUNAKAN REAGEN FENTON $\left(\mathrm{H}_{2} \mathrm{O}_{2} / \mathrm{Fe}^{2+}\right)$
}

\author{
I M. Trimastiya*, I M. S. Negara, O. Ratnayani, I N. Simpen \\ Program Studi Kimia Fakultas Matematika dan Ilmu Pengetahuan Alam Universitas Udayana \\ Jalan Kampus Unud-Jimbaran, Jimbaran-Bali, Indonesia \\ *e-mail: gunt09116@gmail.com
}

\begin{abstract}
ABSTRAK
PET termasuk jenis plastik yang non-degradabel sehingga dapat menimbulkan permasalahan lingkungan. Penelitian ini bertujuan untuk membentuk komposit dengan cross-linking PET dengan selulosa menggunakan inisiator reagen fenton, mengetahui pengaruh penambahan $\mathrm{H}_{2} \mathrm{O}_{2}$ pada reagen fenton yang digunakan sebagai inisiator dalam campuran komposit PET-selulosa terhadap daya serapan air serta laju degradasi pada media tanah basah dan tanah kering. Tahap-tahap yang dilakukan dalam membuat komposit PET-selulosa adalah pemurnian PET menggunakan teknik swelling, dilanjutkan dengan pembentukan komposit PET-selulosa dengan teknik cross-linking melalui reaksi radikal bebas menggunakan fenton $\left(\mathrm{H}_{2} \mathrm{O}_{2} / \mathrm{Fe}^{2+}\right)$ sebagai inisiator dengan variasi jumlah $\mathrm{H}_{2} \mathrm{O}_{2}$ (30 gram, 60 gram, 90 gram). Komposit yang dihasilkan diuji daya serap air dan sifat degradasinya pada media tanah basah dan tanah kering dengan kontrol PET tanpa perlakuan. Karakterisasi dilakukan dengan analisa gugus fungsi menggunakan FTIR serta morfologinya dengan SEM. Hasil penelitian menunjukan pembuatan komposit dengan teknik cross-linking antara polietilen tereftalat dengan selulosa menggunakan reagen fenton sudah berhasil dilakukan dimana laju degradasi komposit PET-selulosa melambat seiring meningkatnya jumlah hidrogen peroksida yang digunakan. Kemudian komposit yang dikubur pada kondisi tanah basah memiliki laju degradasi yang lebih tinggi daripada tanah kering. Pada komposit PETselulosa dengan meningkatnya jumlah $\mathrm{H}_{2} \mathrm{O}_{2}$ yang digunakan maka daya serap air komposit semakin melemah.
\end{abstract}

Kata kunci: degradable, fenton $\left(\mathrm{H}_{2} \mathrm{O}_{2} / \mathrm{Fe}^{2+}\right)$, komposit, PET (Polietilen Tereftalat), selulosa, komposit.

\begin{abstract}
PET is a non-degradable type of plastic that can cause environmental problems. This study aimed to form composites by cross-linking PET with cellulose using Fenton reagent initiator, finding out the effect of the addition of $\mathrm{H}_{2} \mathrm{O}_{2}$ on the fenton reagent used as an initiator in the mixture of PET-cellulose composites to water absorption and the rate of degradation in wet and dry soil media. The steps carried out in making PET-cellulose composites was refining PET using swelling techniques, followed by the formation of PET-cellulose composites by cross-linking through free radical reaction using fenton $\left(\mathrm{H}_{2} \mathrm{O}_{2} / \mathrm{Fe}^{2+}\right)$ as the initiator with the variation of $\mathrm{H}_{2} \mathrm{O}_{2}$ amount (30 grams, 60 grams, 90 grams). The resulting composites were tested for water absorption and degradation properties in wet soil media and dry soil with untreated PET control. Characterization was carried out by functional group analysis using FTIR and its morphology with SEM. The results of the study showed that the composite making using the technique of cross-linking between polyethylene terephthalate and cellulose using fenton reagents was successfully carried out where the degradation rate of PET-cellulose composites slowed as the amount of hydrogen peroxide was used. In PET-cellulose composites, the more amount of $\mathrm{H}_{2} \mathrm{O}_{2}$ used, the weaker the absorption of the composite to water was.
\end{abstract}

Keywords: degradable, fenton $\left(\mathrm{H}_{2} \mathrm{O}_{2} / \mathrm{Fe}^{2+}\right)$, PET (Polyethylene Tephthalate), cellulose, composite.

\section{PENDAHULUAN}

Plastik banyak digunakan dalam berbagai industri pembuatan berbagai material seperti meja, kursi, pot, pintu, lemari, botol, kemasan dan lain- lain. Plastik unggul dalam hal bentuknya yang fleksibel, berbobot ringan, tidak mudah pecah, bersifat transparan/tembus pandang, mudah diberi label dan dibuat dalam aneka warna, dapat diproduksi secara massal, harga relatif murah dan terdapat berbagai jenis pilihan bahan dasar plastik (Siddique, 2008).

Sampah plastik bekas yang dihasilkan oleh masyarakat menimbulkan masalah terhadap lingkungan karena ketidakmampuan mikroorganisme yang terdapat di lingkungan untuk merombak dan menguraikan plastik.

PET (Polietilen Tereftalat) merupakan salah satu jenis plastik yang sering digunakan, khususnya untuk kemasan minuman. 
Meningkatnya jumlah penggunaan PET menyebabkan jumlah sampah PET dengan cepat meningkat pula. Meskipun PET bukan termasuk bahan yang tidak berbahaya, namun PET termasuk jenis plastik yang nondegradable sehingga dapat menimbulkan permasalahan lingkungan. (Siddique, 2008).

Plastik degradabel merupakan alternatif yang perlu dikembangkan untuk memecahkan masalah penanganan sampah plastik. Produksi bahan plastik degradabel mengalami peningkatan seiring dengan meningkatnya kesadaran akan pentingnya kelestarian lingkungan (Pranamuda, 2011).

Dewasa ini, pengunaan material komposit mulai banyak dikembangkan dalam dunia industri. Pada dasarnya material komposit merupakan gabungan dari dua atau lebih material yang berbeda menjadi suatu bentuk unit mikroskopik, yang terbuat dari bermacammacam kombinasi sifat atau gabungan antara serat dan matrik (Jones, 1975).

Telah dilakukan berbagai penelitian yang bertujuan untuk menghasilkan suatu material komposit yang bersifat degradabel seperti yang dilakukan oleh (Simpen, 2013) yang membuat suatu material komposit dengan menggabungkan material plastik polipropilena dengan selulosa yang dicampurkan untuk menghasilkan suatu komposit degradabel.

Selain itu, telah dilakukan pula penelitian oleh (Nurwendi, 2015) yaitu dengan mencampurkan selulosa dari serbuk kayu kamper dengan polietilen menggunakan reagen Fenton sebagai inisiator. Hasil penelitian menunjukan seiring dengan meningkatnya konsentrasi hydrogen peroksida yang digunakan laju degradasi melambat.

Reagen Fenton merupakan inisiator redoks yang terdiri dari reaksi hidrogen peroksida dengan ion besi $\left(\mathrm{Fe}^{2+}\right)$. Besi (II) dioksidasi oleh hidrogen peroksida menjadi besi (III), membentuk radikal hidroksil dan ion hidroksida dalam proses tersebut. Dimana radikal yang terbentuk dalam proses reaksi Fenton berperan sebagai inisiator. Dengan adanya inisiator maka inisiasi, yang merupakan tahap awal polimerisasi, akan berlangsung (Stevens, 2007).

Berdasarkan uraian-uraian diatas maka peneliti tertarik untuk melakukan penelitian tentang pembuatan komposit degradabel dari jenis plastik polietilena tereftalat (PET) dengan selulosa menggunakan reagen fenton $\left(\mathrm{H}_{2} \mathrm{O}_{2} / \mathrm{Fe}^{2+}\right)$ sebagai inisiator dengan metode cross-linking. Hasil komposit yang diperoleh diuji kemampuannya terurai di alam dengan uji degradable serta, dianalisa gugus fungsinya dengan Fourier Transform Infrared Spectroscopy (FTIR), analisa sifat morfologi dengan uji Spectra Electro Magnetic (SEM), serta dianalisa ketahanan terhadap airnya dengan uji daya serap air.

\section{MATERI DAN METODE}

\section{Bahan}

Bahan-bahan yang digunakan dalam penelitian ini antara lain : botol plastik berlogo PET, deterjen, selulosa, fenol $\left(\mathrm{C}_{6} \mathrm{H}_{6} \mathrm{O}\right)$, metanol $\left(\mathrm{CH}_{3} \mathrm{OH}\right), \mathrm{H}_{2} \mathrm{O}_{2} 50 \%, \mathrm{FeSO}_{4} .7 \mathrm{H}_{2} \mathrm{O}$, aquades, gas nitrogen.

\section{Peralatan}

Alat-alat yang digunakan dalam penelitian ini diantaranya: gelas ukur, pipet ukur, pipet volume, gelas beaker, erlenmeyer bertutup, batang pengaduk, neraca analitik, ball filler, hotplate, blender, thermometer, glasswool, aluminium foil, gunting, magnetic stirrer, stopwatch, kapi, shop press, alat pencetak komposit (hot press), Fourier Transform Infrared (FT-IR) dan Scanning Electron Microscope (SEM).

\section{Cara Kerja}

\section{Preparasi sampel limbah PET}

Limbah PET yang diperoleh dari botol plastik berlogo PET pertama-tama dicuci terlebih dahulu dengan detergen. Kemudian botol dikeringkan dan dipotong dengan ukuran $2 \times 2 \mathrm{~mm}$ hingga $4 \times 4 \mathrm{~mm}$. Setelah kering, potongan botol di cuci kembali hingga bersih, kemudian dikeringkan dalam oven selama 3 jam pada suhu $60^{\circ} \mathrm{C}$.

Sampel PET dimasukan kedalam gelas beaker sebanyak 10 gram dan dilarutkan dengan $100 \mathrm{~mL}$ fenol pada suhu $90{ }^{\circ} \mathrm{C}$ sampai larut. Setelah larut, PET diendapkan dengan menambahkan metanol, kemudian difiltrasi dan dikeringkan selama 48 jam pada suhu 40 ${ }^{\circ} \mathrm{C}$ dan selama 3 jam lagi pada suhu $160^{\circ} \mathrm{C}$.

\section{Pembuatan komposit degradable}

Variasi dilakukan dengan menvariasikan dan $\mathrm{H}_{2} \mathrm{O}_{2}$ pada fenton, sementara itu parameter yang dibuat tetap adalah komposisi 
polietilena tereftalat (PET), selulosa, $\mathrm{FeSO}_{4} \cdot 7 \mathrm{H}_{2} \mathrm{O}$ dan waktu reaksi dibuat konstan.

Tabel 1. Komposisi Perbandingan Selulosa : PET : $\mathrm{H}_{2} \mathrm{O}_{2} 50 \%$ : $\mathrm{FeSO}_{4} \cdot 7 \mathrm{H}_{2} \mathrm{O}$

\begin{tabular}{cccc}
\hline $\begin{array}{c}\text { PET } \\
\text { (gram) }\end{array}$ & $\begin{array}{c}\text { Selulosa } \\
\text { (gram) }\end{array}$ & $\begin{array}{c}\mathbf{H}_{2} \mathbf{O}_{2} \\
\mathbf{5 0 \%} \\
\text { (gram) }\end{array}$ & $\begin{array}{c}\mathbf{F e S O}_{4} \cdot \mathbf{7} \\
\mathbf{H}_{2} \mathbf{O} \\
\text { (gram) }\end{array}$ \\
\hline 100,00 & 30,00 & 30,00 & 0.10 \\
100,00 & 30,00 & 60,00 & 0.10 \\
100,00 & 30,00 & 90,00 & 0.10 \\
\hline
\end{tabular}

Mula-mula selulosa dari hasil ektraksi dan polietilena tereftalat (PET) dimasukan kedalam erlenmeyer kemudian ditambahkan reagen fenton sesuai perbandingan pada Tabel 1 . Ke dalam erlenmeyer dialiri gas nitrogen selama 1 jam kemudian ditutup, kemudian dikocok homogen selama 20 menit dan didiamkan selama 24 jam. Setelah 24 jam diaduk kembali dengan blender selama 10 menit.

Pencetakan komposit dilakukan dengan cetakan berukuran $15 \times 18 \mathrm{~cm}$ dengan alat hot press. Mula-mula cetakan disusun kemudian dasar dan tutup cetakan dilapisi dengan aluminium foil kemudian dimasukan 100 gram PET di lapisan paling bawah, campuran pada Tabel 1. dan di lapisan paling atas ditambahkan 100 gram PET cetakan ditutup. Sela-sela atau rongga-rongga yang terlihat pada cetakan ditutup menggunakan glasswool kemudian cetakan dipasang pada alat hot press. Suhu disetting $260^{\circ} \mathrm{C}$ serta tekanan dibuat $100 \mathrm{MPa}$. Setelah suhu tercapai proses pemanasan dibiarkan selama 3 jam. Setelah proses pemanasan selesai alat dimatikan dan cetakan didinginkan selama 24 jam. Setelah selesai komposit dikeluarkan dari cetakan menggunakan shop press.

Hasil komposit degradabel yang diperoleh dianalisa ketahanan terhadap airnya dengan uji daya serap air, diuji kemampuannya terurai di alam dengan uji degradable, dikarakterisasi dengan analisa gugus fungsi dengan uji FT-IR dan analisa sifat morfologi dengan uji SEM.

\section{Pengujian kemampuan menyerap air}

Komposit diuji kemampuan serapan airnya dengan cara mengukur persentase dari berat komposit setelah dilakukan perendaman selama 24 jam. (ASTM D 1037 pada Abdi,M. 2010)
Serapan air dihitung dengan :

Water absorption $(\%)=\left[\left(W_{w}-W_{i}\right) / W_{i}\right] \times 100$

Dimana $: W_{w}=$ berat setelah direndam; $W_{i}=$ berat sebelum direndam

\section{Pengujian sifat degradasi}

Analisa degradasi komposit dilakukan dalam dua kondisi lingkungan, yaitu lingkungan tanah biasa dan lingkungan tanah berair. Mula-mula komposit selulosa-PET dipotong dengan ukuran panjang lebar sebesar $1,5 \times 1,5 \mathrm{~cm}$ dan tebal $0,7 \mathrm{~cm}$ kemudian ditimbang, kemudian dilakukan penguburan dalam tanah biasa dan dalam tanah berair sedalam $30 \mathrm{~cm}$ selama setiap 10 hari dalam 1 bulan. Setiap 10 hari selama 1 bulan, komposit diambil, dicuci sampai bersih, dikeringkan, lalu ditimbangkan. (Pimpan, et al. 2001).

\section{HASIL DAN PEMBAHASAN}

\section{Daya Serap Air Komposit}

Hasil pengujian daya serap air dari komposit dengan variasi $\mathrm{H}_{2} \mathrm{O}_{2}$ sesuai Tabel 1 dapat dilihat pada Tabel 2.

Tabel 2. Daya Serap Air Komposit

\begin{tabular}{|c|c|c|}
\hline $\begin{array}{c}\text { Waktu } \\
\text { Pencelupan }\end{array}$ & Jenis Sampel & $\begin{array}{c}\text { Persentase } \\
\text { Serapan Air } \\
(\%)\end{array}$ \\
\hline 24 Jam & PET & 0,00 \\
\hline 24 Jam & $\begin{array}{l}\text { PET-Selulosa } \\
\mathrm{H}_{2} \mathrm{O}_{2} 30 \text { gram }\end{array}$ & 2,93 \\
\hline 24 Jam & $\begin{array}{l}\text { PET-Selulosa } \\
\mathrm{H}_{2} \mathrm{O}_{2} 60 \text { gram }\end{array}$ & 2,34 \\
\hline 24 Jam & $\begin{array}{l}\text { PET-Selulosa } \\
\mathrm{H}_{2} \mathrm{O}_{2} 90 \text { gram }\end{array}$ & 1,97 \\
\hline
\end{tabular}

Hasil tersebut menunjukan bahwa semakin banyak jumlah $\mathrm{H}_{2} \mathrm{O}_{2}$ maka kemampuan komposit menyerap air akan semakin rendah. Pada komposit dengan penambahan $\mathrm{H}_{2} \mathrm{O}_{2}$ paling banyak diperoleh presentase paling kecil. Hal ini kemungkinan karena kerapatan dari material meningkat akibat banyaknya ikatan yang terjadi antara polimer selulosa dengan PET pada komposit seiring dengan penambahan jumlah $\mathrm{H}_{2} \mathrm{O}_{2}$ yang digunakan sehingga menyebabkan air jadi lebih susah masuk kedalam material kemudian menyebabkan daya serap air menjadi rendah. 


\section{Analisa Komposit dengan SEM (Scanning Electro Microscopy)}

Hasil analisa SEM pada komposit PETSelulosa dapat dilihat pada Gambar 1 .

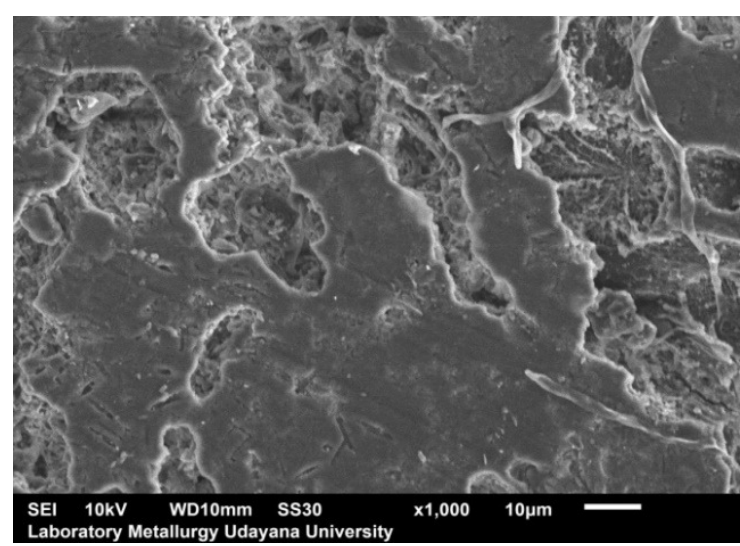

Gambar 1. Hasil Uji SEM komposit PETSelulosa perbesaran 1000x

Gambar 1 menunjukkan permukaan dari komposit PET-Selulosa yang kasar karena kehadiran selulosa. Sedangkan Gambar 2 terlihat permukaan dari PET tanpa selulosa yang rata. Dari kedua gambar tersebut dapat dilihat bahwa cross-linking antara selulosa dengan PET telah terjadi. Hal ini ditegaskan dengan munculnya gundukan yang menempel pada permukaan PET.

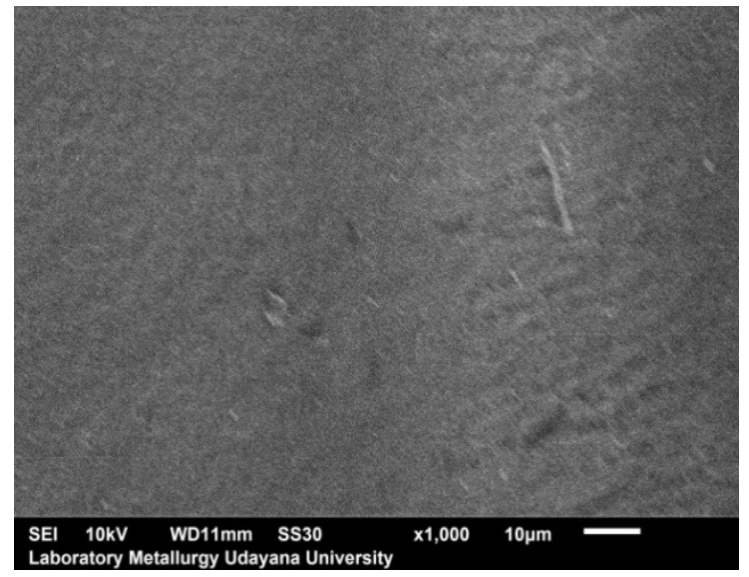

Gambar 2. Hasil Uji SEM PET perbesaran 1000x

\section{Analisa Komposit dengan FTIR (Fourier Transform Infrared Spectroscopy)}

Analisa menggunakan FTIR dilakukan untuk menentukan perubahan gugus fungsi yang dialami oleh polietilen tereftalat (PET) sebelum dan setelah membentuk komposit dengan selulosa, yang ditunjukkan pada Gambar 3.

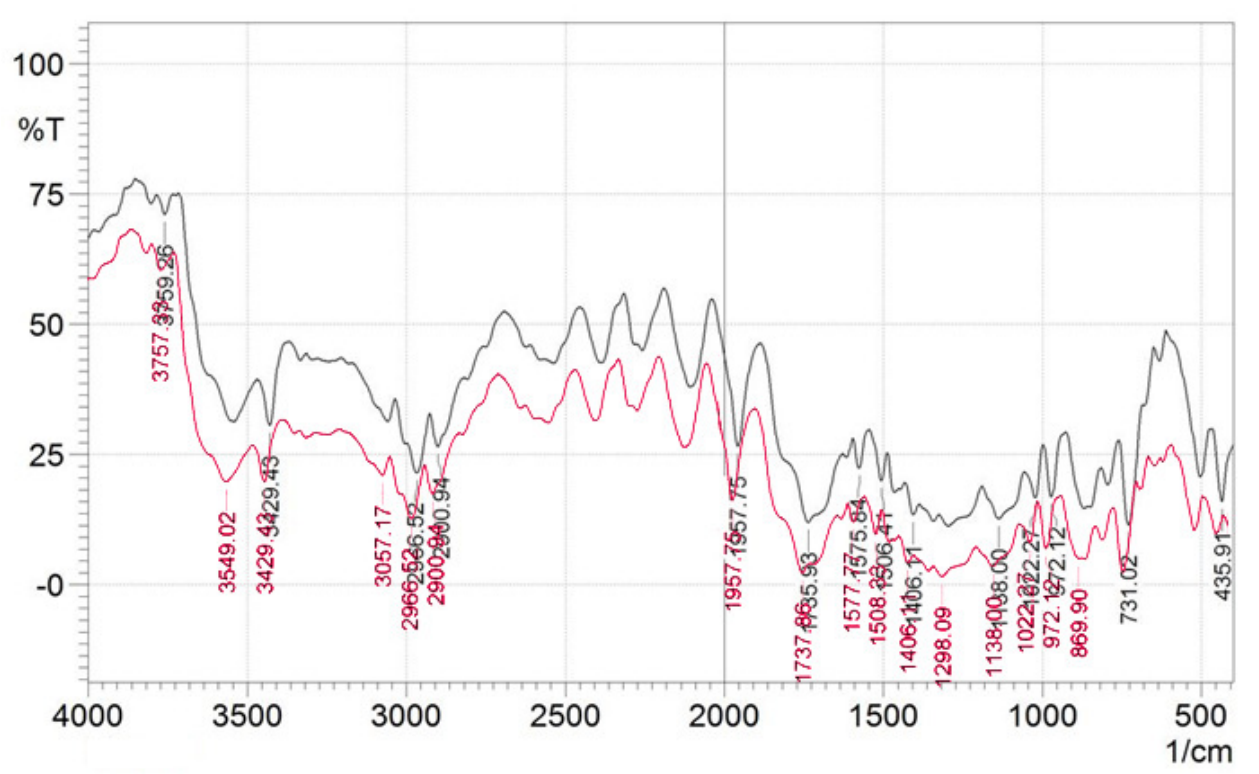

Keterangan: - Kontrol; - Komposit PET-Selulosa dengan $\mathrm{H}_{2} \mathrm{O}_{2} 90$ gram

Gambar 3. Spektra IR Komposit 
Tabel 3. Analisa IR Komposit

\begin{tabular}{lcc}
\hline \multirow{2}{*}{$\begin{array}{l}\text { Gugus } \\
\text { fungsi }\end{array}$} & \multicolumn{2}{c}{ Bilangan gelombang $\left(\mathbf{c m}^{-\mathbf{1}}\right)$} \\
\cline { 2 - 3 } & PET & $\begin{array}{r}\text { PET-Selulosa } \\
\mathbf{H}_{2} \mathbf{O}_{\mathbf{2}} \mathbf{9 0} \mathbf{~ g r}\end{array}$ \\
\hline $\mathrm{O}-\mathrm{H}$ & 3429.43 & 3429.43 \\
$\mathrm{C}-\mathrm{H} \mathrm{sp}{ }^{2}$ & 2966.52 & 2966.52 \\
$\mathrm{C}-\mathrm{H} \mathrm{sp}$ & 2900.94 & 2900.94 \\
$\mathrm{C}=\mathrm{O}$ & 1735.93 & 1737.86 \\
$\mathrm{C}=\mathrm{C}$ & 1575.84 & 1577.77 \\
$\mathrm{C}-\mathrm{C}$ & 1138.00 & 1138.00 \\
$\mathrm{C}-\mathrm{O}$ & 1022.27 & 1022.27 \\
\hline
\end{tabular}

Berdasarkan Tabel diatas, spektra IR PET sebelum pencangkokan menunjukkan serapan dengan puncak yang kuat. Pita serapan pada film ini terlihat pada daerah $3429.43 \mathrm{~cm}^{-1}$ yang merupakan vibrasi gugus $\mathrm{O}-\mathrm{H}$ dan pada daerah $2966.52 \mathrm{~cm}^{-1}$ yang merupakan vibrasi gugus C$\mathrm{H} \mathrm{sp}{ }^{2}$, sedangkan pada bilangan gelombang $2900.94 \mathrm{~cm}^{-1}$ merupakan vibrasi gugus $\mathrm{C}-\mathrm{H}$ $\mathrm{sp}^{3}$, kemudian pada bilangan gelombang $1735.93 \mathrm{~cm}^{-1}$ merupakan vibrasi gugus $\mathrm{C}=\mathrm{O}$, untuk bilangan gelombang $1575.84 \mathrm{~cm}^{-1}$ merupakan vibrasi gugus $\mathrm{C}=\mathrm{C}$. Selanjutnya pada bilangan gelombang $1138.00 \mathrm{~cm}^{-1}$ merupakan gugus $\mathrm{C}-\mathrm{C}$ kemudian pada bilangan gelombang 1022.27 vibrasi gugus C-O. Pitapita serapan ini merupakan serapan khas untuk PET pada bilangan gelombang yang disebutkan di atas. Pada PET muncul bilangan gelombang O-H kemungkinan karena pengotor yang ikut terbawa saat proses pencetakkan. Jika spektrum pada PET kontrol dibandingkan dengan hasil komposit hasil cross-linking, maka dapat dilihat tidak terlalu banyak perbedaan pada spektrum serapannya, hal ini karena kesamaan gugus yang terdapat pada selulosa dan PET.

Spektrum PET dan PET-Selulosa dengan berbagai variasi $\mathrm{H}_{2} \mathrm{O}_{2}$ memiliki beberapa serapan yang sama. Hal ini menunjukkan bahwa modifikasi film PET akan tetap memberikan spektrum inframerah yang sama dan proses cross-linking sehingga tidak akan mempengaruhi puncak serapan pada film PET murni. Hal ini menunjukkan proses reaksi radikal bebas pada pembentukan komposit tidak akan mengubah struktur asli dari PET.

\section{Laju Degradasi Pada Uji Degradasi}

Penguburan spesimen komposit degradabel pada dua jenis tanah (tanah kering dan tanah basah) bertujuan untuk melihat tingkat degradasinya oleh alam karena salah satu tempat akhir kemasan plastik adalah kembali ke tanah. Data penurunan berat hasil pengomposan spesimen uji dapat dilihat pada Tabel 4.

Tabel 4 Data Laju Degradasi (\%) Spesimen Komposit Degradable Penguburan Dalam Tanah

\begin{tabular}{|c|c|c|c|c|c|c|}
\hline \multirow{2}{*}{$\begin{array}{c}\text { Jenis } \\
\text { Sampel }\end{array}$} & \multicolumn{3}{|c|}{$\begin{array}{c}\text { Tanah Kering } \\
\text { (Hari) }\end{array}$} & \multicolumn{3}{|c|}{$\begin{array}{c}\text { Tanah Basah } \\
\text { (Hari) }\end{array}$} \\
\hline & 10 & 20 & 30 & 10 & 20 & 30 \\
\hline PET & 0,00 & 0,00 & 0,00 & 0,00 & 0,00 & 0,00 \\
\hline $\begin{array}{c}\text { PET- } \\
\text { Selulosa } \\
\mathrm{H}_{2} \mathrm{O}_{2} 30 \mathrm{~g}\end{array}$ & 0,17 & 0,17 & 0,17 & 0,52 & 0,52 & 0,52 \\
\hline $\begin{array}{c}\text { PET- } \\
\text { Selulosa } \\
\mathrm{H}_{2} \mathrm{O}_{2} 60 \mathrm{~g}\end{array}$ & 0,14 & 0,15 & 0,15 & 0,47 & 0,49 & 0,49 \\
\hline $\begin{array}{c}\text { PET- } \\
\text { Selulosa } \\
\mathrm{H}_{2} \mathrm{O}_{2} 90 \mathrm{~g}\end{array}$ & 0,12 & 0,11 & 0,11 & 0,43 & 0,44 & 0,42 \\
\hline
\end{tabular}

Penguburan spesiman dilakukan pada 2 jenis kondisi tanah selama 30 hari dengan pengamatan setiap 10 hari. Berdasarkan Tabel 4. di atas memperlihatkan laju degradasi yang tidak begitu besar. Suatu penelitian yang telah dilakukan oleh Northrop DM, Rowe WF (1987) dalam jurnal Juergen Puls (2010) yang mempelajari efek lingkungan tanah terhadap degradasi selulosa menyatakan bahwa selulosa akan menunjukkan hasil yang signifikan selama 2 bulan dalam tanah yang basah (lembab) dan akan hancur seluruhnya dalam waktu $4-9$ bulan. Namun demikian, besarnya penurunan massa spesimen matriks polimer komposit sejalan dengan lamanya waktu penguburan. Harga penurunan massa komposit degradabel yang terbesar adalah pada penguburan dalam tanah basah kemudian tanah kering. Hal ini mungkin disebabkan karena jumlah nutrisi dalam tanah basah lebih banyak dari tanah kering. Oleh karena itu, terjadi kinerja yang sinergis antara kegiatan beberapa mikroba (Basuki Wirjosentono, 1998).

\section{KESIMPULAN}

Berdasarkan penelitian yang telah dilakukan, didapatkan kesimpulan bahwa : Laju degradasi komposit PET-selulosa melambat seiring meningkatnya jumlah hidrogen peroksida yang digunakan. Komposit 
yang dikubur pada kondisi tanah basah memiliki laju degradasi yang lebih tinggi daripada tanah kering.Pada komposit PETselulosa meningkatnya jumlah $\mathrm{H}_{2} \mathrm{O}_{2}$ yang digunakan maka daya serap air komposit semakin melemah.

\section{UCAPAN TERIMA KASIH}

Penulis mengucapkan terima kasih kepada semua pihak yang telah membantu dalam menyelesaikan penelitian ini.

\section{DAFTAR PUSTAKA}

Abdi, Muhamad. 2010. Pengaruh Variasi Penambahan Additive $\mathrm{CaCl}_{2}$ Terhadap Karakteristik Fisik dan Kekuatan Lentur Komposit Semen Serbuk Aren (Arenga Pinnata) [Skripsi]. Surakarta (ID): Universitas Sebelas Maret.

Wirjosentono B., Lela, I. D.1998. Struktur dan Sifat Mekanis Polimer. Medan: USU Press.

Jones, R. M. 1975. Mechanics of Composite Materials. Washington DC: Scripta Book Company.

Juergen P., Steven A. W. dan Dirk H. 2010. Degradation of Cellulose Acetate-Based Materials: A Review. J Polym Environ 11(19) :152-165.

Nurwendi, H., Simpen I N. dan Sutha Negara I M. 2015. Sintesis Komposit Selulosa
Serbuk Gergaji Kayu Kamper-Limbah Plastik LDPE (Low Density Poliethylene) Dengan Reagen Fenton Sebagai Agen Pengkopling. Jurnal Kimia 10 (1) : 89-95.

Pimpan, V., Ratanarat, K., Pongchawanakul, M. 2001. Preliminary Study on Preparation of Biodegradable Plastic from Modified Cassava Starch. Journal Science Res. Chulalongkorn University, 26 (2) : 117-126.

Pranamuda, H. 2011.Pengembangan Bahan Plastik Biodegradabel Berbahan Baku Pati Tropis. Jakarta: Badan Pengkajian dan Penerapan Teknologi.

Siddique, Raffat, 2008. Waste Material and By-Product in Concrete: Recycled/Waste Plastic. Berlin: Springer Verlog Berlin Heidberg. 93-120.

Silverstein, R.M. 1984. Penyidikan Spektrometrik Senyawa Organik. Terjemahan A.J. Hatomo dan Any Viktor Purba. Edisi Keempat. Jakarta: Pernerbit Erlangga.

Simpen, I N. dan Sutha Negara, I M. 2013. Sintesis Komposit SelulosaPolipropilena Dengan Reagen Fenton Sebagai Agent Pengkopling, Jurnal Kimia 7 (1):1907-9850.

Stevens, M. 2007. Kimia Polimer, Diterjemahan oleh Iis Sopya,. Jakarta: Pradnya Paramita. 